\title{
Thermal performance of meso-scale oscillatory baffled reactors
}

\author{
Safaa M. R. Ahmed ${ }^{\text {a, b, }}{ }^{,}$, Richard Law ${ }^{\text {a }}$, Anh N. Phan ${ }^{\text {a }}$, Adam P. Harvey ${ }^{\text {a }}$ \\ ${ }^{a}$ School of Engineering, Newcastle University, Merz Court, Claremont Road, Newcastle Upon Tyne NE1 7RU, UK \\ ${ }^{\mathrm{b}}$ Department of Chemical Engineering, College of Engineering, Tikrit University, Tikrit, Salah ad Din, Iraq. \\ *Corresponding Author (Email: s.m.r.ahmed@ncl.ac.uk, mobile: 07774101215)
}

\begin{abstract}
This study reports the evaluation of heat transfer characteristics and pressure drops in three designs of mesoscale oscillatory baffled reactors over the net flow range $\mathrm{Re}_{\mathrm{n}}=60-2500$ and the oscillatory flow range $\mathrm{Re}_{\mathrm{o}}$ $=0-1600$. The three designs were the oscillatory central baffled reactor (OCBR), the oscillatory helical baffled reactor (OHBR), and the oscillatory orifice baffled reactor (OOBR). The designs were evaluated in terms of "thermal performance" to take the heat transfer and pressure drop into account.

Interestingly, in all designs the pressure drop was observed to decrease with increasing oscillation, due to some degree of energy recovery. In all cases, oscillating the flow significantly enhanced the Nusselt number by upto a maximum of around 10-fold. The meso-OBRs were shown to achieve higher thermal performances than steady flows in smooth tubes in all cases. Up to $480 \%, 460 \%$, and $300 \%$ improvements in thermal performance was achieved for the OHBR, OCBR, and OOBR, respectively. The OHBR exhibited the lowest pressure drop, resulting in the highest thermal performance of the designs investigated here. Hence, on the basis of this study, the OHBR design is recommended. New empirical correlations for predicting pressure drop and Nusselt number were established for each design, with data mostly lying in the range $\pm 30 \%$ of the correlations.
\end{abstract}

Keywords: Oscillatory Baffled Reactor; Heat transfer enhancement; Process Intensification

\section{Introduction}

Oscillatory baffled reactors (OBRs) have demonstrated increased convective heat transfer over conventional heat transfer devices such as heat exchangers via their combination of baffles (passive technique) and oscillation (active technique) $[1,2,3]$. The oscillatory baffled reactor (OBR) is an intensified 
reactor consisting of a tube containing periodically-spaced baffles in which the net flow through the reactor has an oscillatory flow superimposed upon it. Consequently, the OBR is able to achieve high degrees of mixing at typically laminar-regime (net) flowrates. $[4,5]$, thereby enhancing transport of mass and energy.

The flow behaviour in OBRs is governed by the net flow Reynolds number $\left(R e_{n}\right)$ which represents the net flow condition, oscillatory Reynolds number $\left(R e_{o}\right)$ which describes the oscillation intensity, velocity ratio $(\psi)$ which is the ratio of oscillatory \& net flow Reynolds number, and the Strouhal number (St) which describes eddy propagation, defined as:

$$
\begin{aligned}
& R e_{n}=\frac{\rho u D}{\mu} \\
& R e_{o}=\frac{x_{0} \omega \rho D}{\mu} \\
& \psi=\frac{R e_{0}}{R e_{n}} \\
& S t=\frac{D}{4 \pi x_{0}}
\end{aligned}
$$

Where $\rho$ is the fluid density $\left(\mathrm{kg} / \mathrm{m}^{3}\right), u$ the superficial net flow velocity $(\mathrm{m} / \mathrm{s}), D$ the pipe diameter $(\mathrm{m}), \mu$ the fluid viscosity $(\mathrm{kg} / \mathrm{ms}), x_{0}$ is the centre-to-peak amplitude of oscillation and $\omega$ the angular frequency of the oscillation cycle ( $\omega=2 \pi f$, where $f$ is the frequency of oscillation in $\mathrm{Hz})$.

Only limited studies have been completed in the areas of thermal design and pressure drop in OBRs have been performed, and as a result few reliable design equations exist. Mazubert et al (2016) studied the effect of baffle configurations (single orifice baffles, disc-and-donut baffles, and helical blades) on the pressure drop and power density in a $15 \mathrm{~mm}$ OBR in a numerical modelling study [6]. The disc-and-donut design exhibited the highest pressure drop $\left(2.84 \mathrm{kPa} \mathrm{m}^{-1}\right)$ and power consumed $\left(189.6 \mathrm{~W} \mathrm{~m}^{-3}\right)$, while the singleorifice design had the lowest pressure drop $\left(0.73 \mathrm{kPa} \mathrm{m}^{-1}\right)$. González-Juárez et al (2017) reported the effect of the orifice baffle configuration in terms of the number of holes (orifice) on the pressure drop [7], i.e. pressure drop increased by 3 -fold in the 43 orifices design compared with the single orifice design because an increase in the orifice number leads to increasing friction. Mackley and Stonestreet [1] reported the $\Delta \mathrm{P}$ in a standard-scale orifice-baffle $\mathrm{OBR}$ and the $\Delta \mathrm{P}$ in the OBR decreased with $\mathrm{Re}_{\mathrm{o}}$ at oscillation frequency of $\leq 6 \mathrm{~Hz}$.

The same study [1] also reported that $N u$ enhanced by upto 30-fold with presence of oscillatory flow compared to the steady flow. Correlations between $N u$ and operating conditions were also established as shown in Eq. 5. However, this correlation, Eq. 5, is only valid for low oscillation conditions, $R e_{o} \leq 800$, and 
high Prandtl number, Pr= 73. A recent study [3] developed a new correlation, Eq. 6 (a) and (b), for predicting $\mathrm{Nu}$ for a wider range of oscillation intensities and liquids with lower Prandtl numbers.

$$
\begin{aligned}
& N u=0.0035 \operatorname{Re}_{n}^{1.3} \operatorname{Pr}^{1 / 3}+0.3\left[\frac{R e_{0}^{2.2}}{\left(R e_{n}+800\right)^{1.25}}\right] \quad \operatorname{Re}_{\mathrm{o}} \leq 800 \quad \operatorname{Pr}=73 \quad \text { [1] } \\
& N u=0.022 \operatorname{Re}_{n}^{0.7} \operatorname{Pr}^{0.3} \operatorname{Re}_{o}^{0.44} \quad 0 \geq \operatorname{Re}_{\mathrm{o}} \leq 1300 \quad \operatorname{Pr}=4.4-24.3 \quad \text { [3] } \\
& N u=0.52 \operatorname{Re}_{n}^{0.7} \operatorname{Pr}^{0.3} \quad \operatorname{Re}_{\mathrm{o}}>1300 \quad \operatorname{Pr}=4.4-24.3 \quad \text { [3] (6b) }
\end{aligned}
$$

Stephens and Mackley (2001) [2] confirmed that the heat transfer coefficient is dependent on the oscillation intensity. Recently Solano et al [8] reported in a numerical study that Nusselt number increased with oscillatory Reynolds number, $R e_{o}$, due to radial mixing induced as a result of the interaction between oscillatory flow and the helical baffle.

To date, the effect of scale and baffle design on the heat transfer enhancement and pressure drops in meso-OBRs is not clear, as the existing experimental studies all used the conventional design of OBR (orifice baffles, $>12 \mathrm{~mm}$ diameter). Therefore, the aim of this work was to investigate heat transfer and pressure drop in a mesoscale-OBR fitted with three designs of baffles (helical, central, and orifice). The resulting data will be used to validate existing correlations/design equations for use at the meso-scale, or to suggest updated versions more suitable to this unique scale of OBR.

\section{Experimental}

\subsection{Equipment and Methods}

A meso-scale shell-and-tube was used in a horizontal orientation, to avoid the effect of gravity on the fluid, to conduct the heat transfer experiments and pressure drop measurements. The tube was $5.0 \mathrm{~mm}$ i.d. 316 stainless steel with wall thickness $0.9 \mathrm{~mm}$ while the outer-tube (shell-side) was $21.5 \mathrm{~mm}$ i.d. stainless steel tube. The active length of the heat exchanger was $100 \mathrm{~mm}$. Three different types of baffles, single-orifice baffle, central-axial baffle, and helical baffle, with the same baffle spacing $(l=0.5 D)$ were inserted into the $5 \mathrm{~mm}$ i.d. tube as shown in Fig. 1, and detailed shown in Table 1. To provide fluid oscillation, each heat exchanger was connected with a "Confluent PVM" syringe pump (Eurodyne Ltd.) via PTFE tubing and a custom-built Swagelok union. The amplitude (centre-to-peak) was controlled by varying the volume of the displaced liquid, whilst the frequency was controlled by varying the speed and acceleration settings of the plunger. Both oscillation amplitude and frequency were controlled via text input commands using "Sapphire Commander" software. The shell-side cold water was provided by a chiller (HAAKE FISONSDC3). The temperature was maintained at $15^{\circ} \mathrm{C}$ and a constant flow rate of $1.6 \mathrm{l} / \mathrm{min}$. The heat exchanger 
was heavily insulated to ensure a heat balance within experimental error. Around 225 runs were completed in total during this study to measure the pressure drops and calculate the OBR-side heat transfer Nusselt number. Each individual run was completed in triplicate in order to evaluate the random error (standard deviation), which on average was $\pm 8 \%$ for the Nusselt number and $\pm 6 \%$ for the pressure drop.

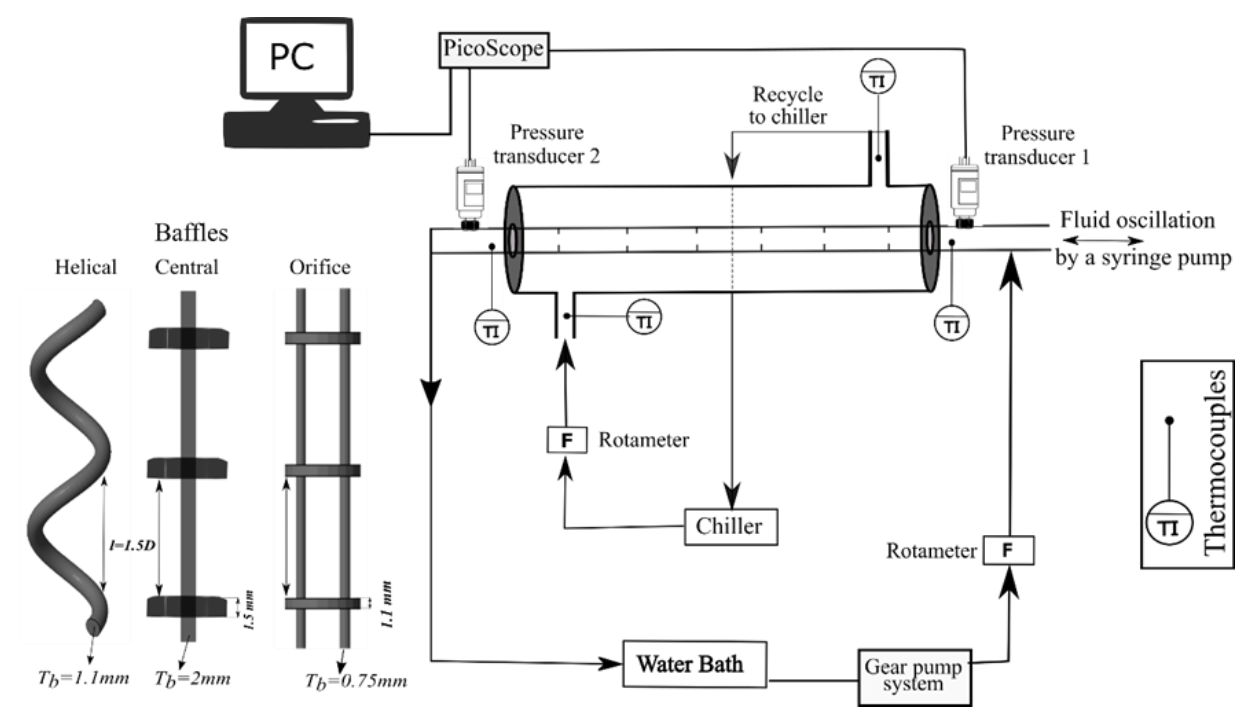

Fig. 1. Schematic diagram of shell-tube OBR and baffle configurations

The OBR-side was connected to a water bath (VWR, MX7LR-20, low profile) to maintain the hot-side inlet temperature at $50^{\circ} \mathrm{C}$. The hot water coming from the water bath was supplied to the OBR-side using a Greylor PQ-12 gear pump powered by a DC power supply (Digimess PM3006) via a 1/8" o.d. flexible tube, as shown in Fig. 2. Fluid temperatures were measured at the heat exchanger terminals using four $1.5 \mathrm{~mm}$ diameter K-type thermocouples, which were calibrated according to BS1041-4. A Pico Log TC-08 was used to record the thermocouple data. Omega FL-2053, Fl-2045, and FL-2051 rotameters were used to set the OBR net flow and shell-side flow rate respectively. The ranges of the operational parameters, the OBRside net flow, and oscillation conditions are listed in Table 2. The effect of Strouhal number was only investigated in pressure drop experiments as it has previously been shown to have a negligible effect on the Nusselt number $[1,3]$.

Table 1. Baffle specifications

\begin{tabular}{|c|c|c|c|}
\hline $\begin{array}{c}\text { Central-axial } \\
\text { baffle }\end{array}$ & $\begin{array}{c}\text { Helical } \\
\text { baffle }\end{array}$ & $\begin{array}{c}\text { Orifice } \\
\text { baffle }\end{array}$ \\
\hline
\end{tabular}




\begin{tabular}{|l|c|c|c|}
\hline $\begin{array}{l}\text { Supporting rod } \\
\text { thickness, } T_{b}, \mathrm{~mm}\end{array}$ & 2 & - & 0.75 \\
\hline Baffle thickness, mm & 1.5 & 1.1 & 1.1 \\
\hline Orifice diameter, $d_{o,} \mathrm{~mm}$ & 1.71 & 3.65 & 2.375 \\
\hline $\begin{array}{l}\text { Open cross -sectional } \\
\text { area, } \alpha\end{array}$ & 0.13 & 0.59 & 0.25 \\
\hline
\end{tabular}

Table 2. Range of operational parameters tested in study

\begin{tabular}{|l|c|}
\hline Range of net flow rates $(\mathrm{mL} / \mathrm{s})$ & $0.167-0.533$ \\
\hline Net flow Reynolds number, $R e_{n}$ & $61-2400$ \\
\hline Range of centre-to-peak oscillation amplitude $(\mathrm{mm})$ & $0.00-6.4$ \\
\hline Range of oscillation frequency $(\mathrm{Hz})$ & $0.00-5.5$ \\
\hline Range of oscillatory flow $\mathrm{Re}_{\mathrm{o}}$ & $0-1550$ \\
\hline Range of Strouhal number, $\mathrm{St}$ & $0-0.07$ \\
\hline
\end{tabular}

The experimental procedure for thermal evaluation was adapted from a previous study [3], summarised as follows:

1. OBR-side fluid was circulated around the water-bath loop until a steady-state temperature of $50^{\circ} \mathrm{C}$ was observed.

2. The flow-rates of both fluids were set, followed by the oscillatory flow condition.

3. Terminal temperature readings were taken once the rig was deemed to be in steady-state as indicated by observing readings which are approximately constant with time (this took on average 10-20 minutes per run)

4. Each experimental run was performed in triplicate.

In addition, the pressure-drop on the OBR-side was measured using two Gems Sensors, Gauge Pressure Sensor (350mbar gauge max, accuracy $0.25 \%$ of full scale), fixed at the tube terminals and connected to a PC via a PicoScope 2000 series as shown in Fig. 1. The signals from the pressure transducers were analysed using PicoScope software. In this study about 15000 data points were collected for each run (between 5-30 complete pressure waves, depending on the particular frequency being used) and the pressure drop was the time-averaged difference between the inlet and outlet. Again, measurements were taken once the system was deemed to be in a quasi-steady state (evaluated based on signal from each pressure transducer) and each run was performed in triplicate. 


\section{Results and Discussion}

\subsection{OBR-side pressure drop, $\triangle P$}

\subsubsection{Effect of net flow on $\triangle P$}

Fig. 2 shows the dependence of pressure drop, $\Delta P$, on net flow, $\operatorname{Re}_{\mathrm{n}}$, in all the meso-OBR designs for nonoscillatory flow.

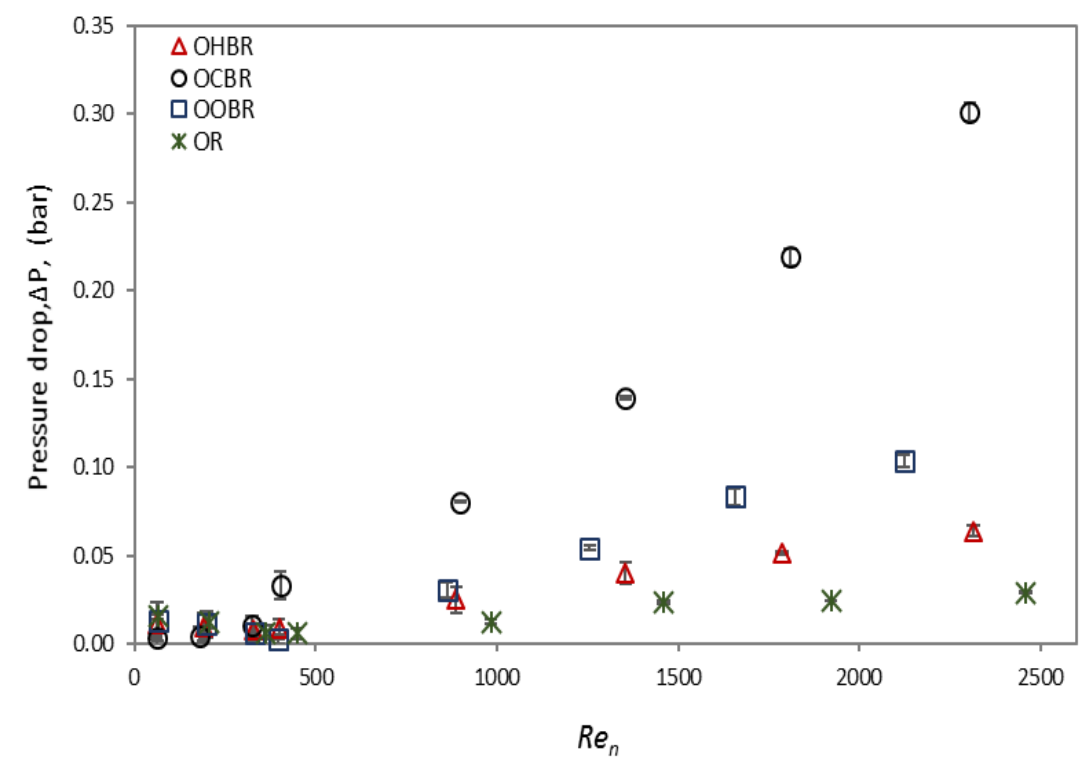

Fig. 2. Dependence of pressure drop on net flow, $R_{n}$, in the meso-OBRs: oscillatory helical baffled mesoreactor (OHBR), oscillatory central baffled meso-reactor (OCBR), oscillatory orifice baffled mesoreactor $(O O B R)$, oscillatory un-baffled meso-reactor $(O R)$ at $\operatorname{Re}_{o}=0$.

Fig 2 shows that the pressure drop is approximately constant for each design of meso-OBR (including for the smooth tube, OR) when $R e_{n} \leq 400$, suggesting that the flow in each case is laminar under these conditions. At $R e_{n}>400$, the pressure drop for the baffled cases rises sharply in relation to the unbaffled case, suggesting that this is the point of transition from the laminar regime (towards turbulence) for the cases where baffles are present. This early onset to transitional and/or turbulent flow is likely due to detachment around the baffle edges, causing turbulent characteristics in the flow such as vortices.

The pressure drop in the OCBR was substantially higher than the other designs: factors of 3, 5 and 15 greater than the OOBR, OHBR, and OR, respectively. This is probably due to the blockage in the midline flow resulting in higher shear stress $[6,10]$. The OOBR showed a greater $\Delta \mathrm{P}$ than the OHBR (factor of around 2.6), likely due to the combined effect of the narrow orifice diameter and sharp baffle edge generating a high degree of shear stress (although less than that generated in the OCBR). The OHBR exhibited the lowest pressure drop, as the helical baffle would be expected to generate the lowest shear stress $[6,11]$. These results agree well with the simulation results in Mazubert et al (2016) [6] where the 
reversed flow in the disc-and-donut geometry resulted in many vortices with different sizes whilst in the single orifice design the reversed flow was governed by stream lines.

\subsubsection{Effect of oscillation on $\Delta P$}

Fig. 3 (a) and (b) present the pressure drop measured in the meso-OBRs versus the oscillation intensity at net flows of $R e_{n}=645$ (Fig. 3a) and $R e_{n}=965$ (Fig. 3b).
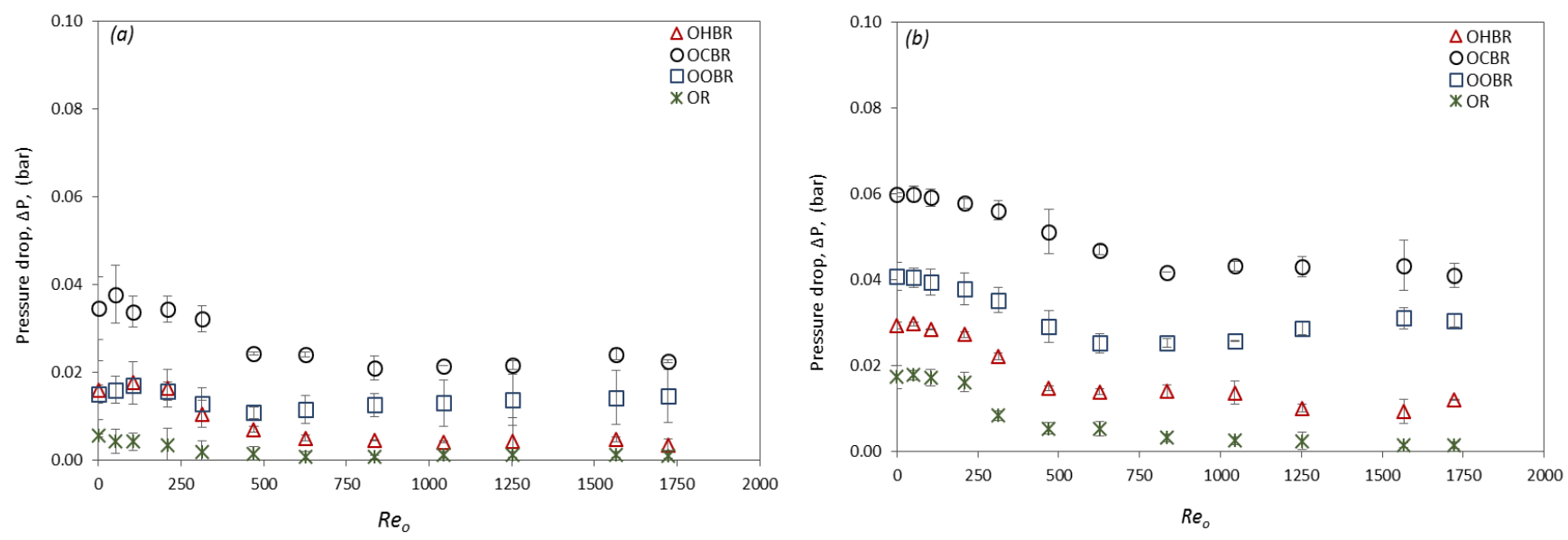

Fig. 3. Dependence of pressure drop on oscillatory flow, $R e_{o}$, in the meso-OBRs: oscillatory helical baffled meso-reactor (OHBR), oscillatory central baffled meso-reactor (OCBR), oscillatory orifice baffled meso-reactor (OOBR), oscillatory un-baffled meso-reactor $(O R)$ at a) $R e_{n}=645$, and b) $R e_{n}=965$

Fig. 3 shows that for each baffle design (and the unbaffled case) the pressure drop decreases with $\mathrm{Re}_{\mathrm{o}}$ until around $\mathrm{Re}_{\mathrm{o}} \geq 500$ when it plateaus. A similar trend was observed by [1] for oscillation frequencies of less than $6 \mathrm{~Hz}$ (as employed in this study), albeit at larger scale and over a smaller parametric range, and it was attributed to likely energy recovery due to unwinding of the vortices around the baffle edge during flow reversal. The OCBR again exhibited the highest $\triangle \mathrm{P}$, followed by the OOBR and OHBR, for the same reasons described in 3.1.1. 


\subsubsection{Effect of Strouhal number}

Fig. 4 (a) - (c) presents the dependence of the OBR pressure drop on Strouhal number in each design of meso-OBR: helical baffled-OBR (Fig. 4a), orifice baffled-OBR (Fig. 4b), and central baffled-OBR (Fig. 4c) at net flows of $R e_{n}=330$ and 309.
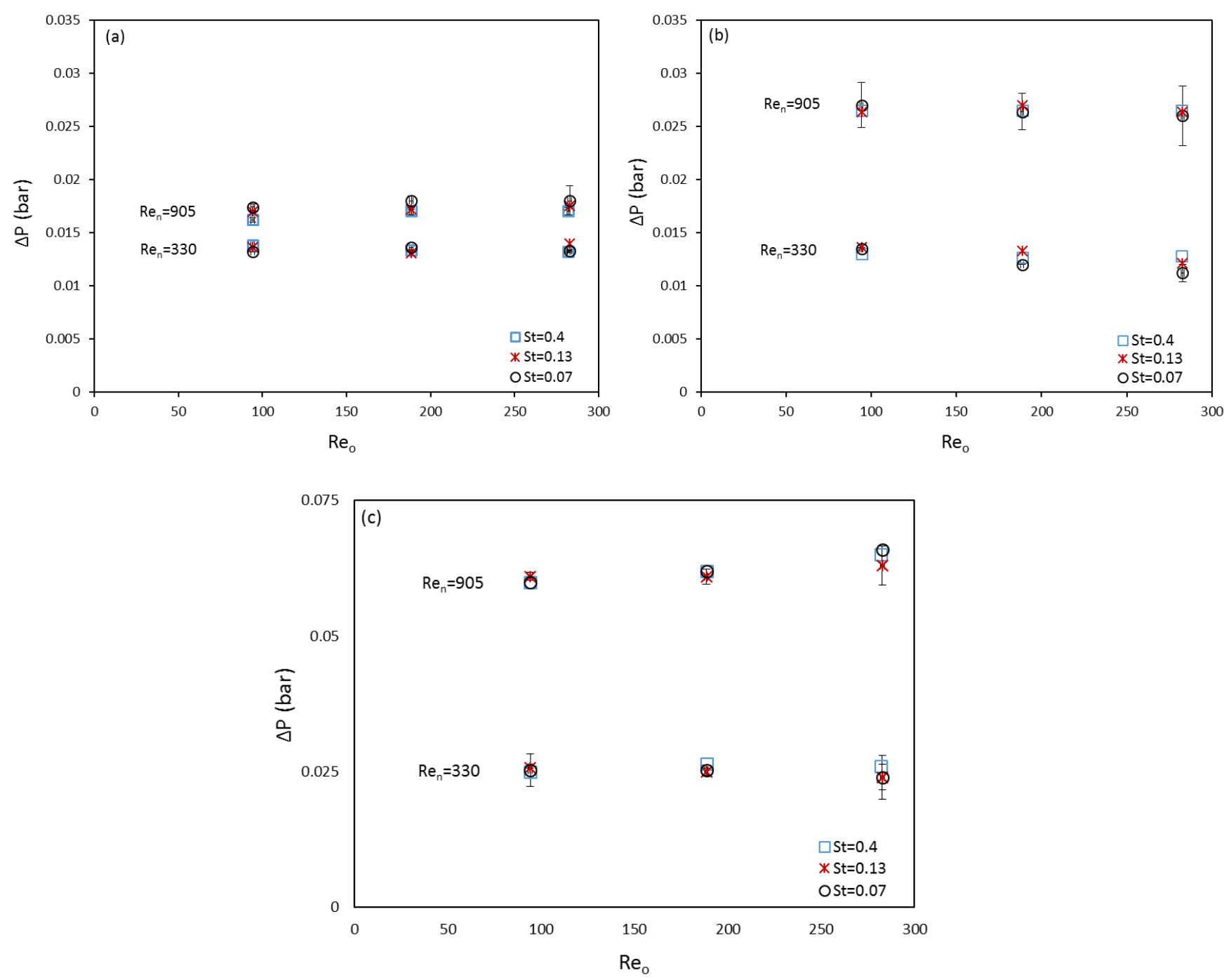

Fig. 4. Dependence of pressure drop on Strouhal number, St, in the meso-OBRs at $R_{n}=330$ and $R e_{n}=905:$ a) oscillatory helical baffled meso-reactor (OHBR), b) oscillatory orifice baffled meso-reactor $(O O B R)$, and c) oscillatory central baffled meso-reactor (OCBR).

It can be seen in Fig. 4 that the Strouhal number has a negligible effect on the pressure drop at both net flows, and for every baffle type. This implies that the pressure drop is dependent on the maximum velocity of the flow oscillation $\left(2 \pi \mathrm{fx}_{\mathrm{o}}\right)$ rather than the individual components which make up this velocity (frequency, amplitude). 


\subsubsection{Correlation to predict pressure drop in meso-OBRs}

The pressure drop in the OBRs is clearly a function of the net and oscillatory flow. Hence, correlations were developed as shown in Equations 7 (a)-(c) and 8 (a)-(c) over a range of conditions. The correlation constants and exponents were fitted using the Microsoft Excel solver add-in (GRG non-linear algorithm). The correlations show that the pressure drop per unit length $(\mathrm{L}, \mathrm{m})$ showed the same behaviour for each design of meso-OBR with respect to $\mathrm{Re}_{\mathrm{n}}$ and $\mathrm{Re}_{\mathrm{o}}$. Only the correlation constant changes by design, and the size of each constant is roughly correlated to the channel blockage of each baffle (see Table 1).

The correlations were validated by plotting the model prediction against the experimental data as shown in Fig. 5. The results show that most of the data falls within $\pm 30 \%$ confidence limits, thereby confirming the validity of these correlations for predicting pressure drop for the OBR designs used within the range of experiments investigated here. The $\mathrm{R}^{2}$ values for the helical, orifice and central baffle designs were $94 \%$, 96\% and 94\% respectively. It should also be noted that this is a purely phenomenological model, based only on the dataset presented in this paper. It is intended for use in design purposes of meso-OBRs of the same (or similar) design. Further validation is required before it should be used outside of the parametric range described in this work.

At $0<R e_{o} \leq 105$ :

$$
\begin{array}{llrl}
\Delta P / L & =5.8 \times 10^{-6} R e_{n}^{1.2} & & \text { Helical baffle design, OHBR } \\
\Delta P / L & =9.46 \times 10^{-6} R e_{n}^{1.2} & & \text { Orifice baffle design, OOBR } \\
\Delta P / L & =2.7 \times 10^{-5} R e_{n}^{1.2} & & \text { Central axial baffle design, OCBR }
\end{array}
$$

\section{At $105<R e_{o} \leq 1800$ :}

$$
\begin{array}{llrl}
\Delta P / L & =3.62 \times 10^{-6} R e_{o}^{-0.2} R e_{n}^{1.4} & & \text { Helical baffle design, OHBR } \\
\Delta P / L=6.1 \times 10^{-6} R e_{o}^{-0.2} R e_{n}^{1.4} & & \text { Orifice baffle design, OOBR } \\
\Delta P / L & =10.6 \times 10^{-6} R e_{o}^{-0.2} R e_{n}^{1.4} & & \text { Central axial baffle design, OCBR }
\end{array}
$$




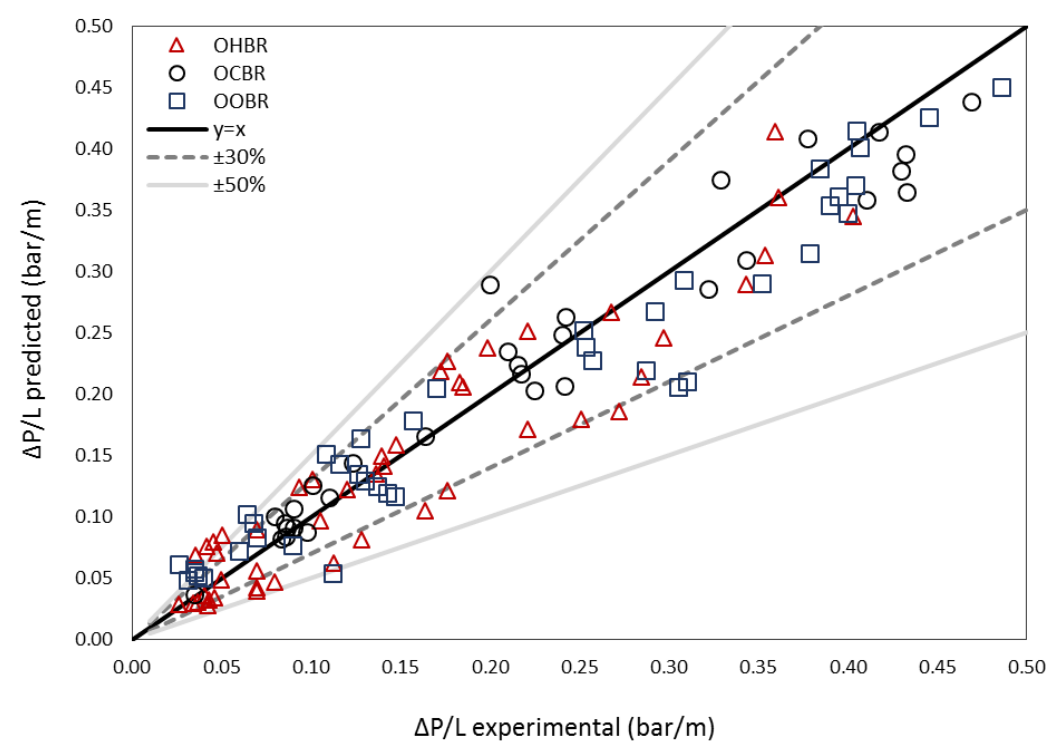

Fig. 5: Comparison of pressure drop prediction by correlation and experimental for the three OBRs: oscillatory helical baffled meso-reactor (OHBR), oscillatory central baffled meso-reactor (OCBR), oscillatory orifice baffled meso-reactor (OOBR), oscillatory un-baffled meso-reactor $(O R)$.

\subsection{OBR-side Nusselt number}

\subsubsection{Nusselt number calculation}

To calculate the Nusselt number of the OBR, the methodology from our previous study was adopted [3]. This is briefly summarised as follows (please see [3] for detailed methodology):

1. A Wilson plot was completed to evaluate the combined thermal resistance of convection on the shell-side and conduction through the heat exchanger wall. For reference, this was $1.89 \times 10^{-4}$ $\mathrm{Km}^{2} / \mathrm{W}$. The overall thermal resistance recorded throughout the experimental programme varied from $0.005-0.0005 \mathrm{Km}^{2} / \mathrm{W}$. Therefore, the combined shell-side and wall resistances never account for more than $38.6 \%$ of the total resistance ensuring that the OBR-side resistance was always dominant, hence confirming the validity of the method.

2. The log-mean temperature difference and heat exchanger duty was calculated using the recorded temperatures at the heat exchanger terminals.

3. The overall heat transfer coefficient was found by rearrangement of Eq. 9.

4. The thermal resistance of the OBR-side could be found by rearrangement of the thermal resistances in series model (Eq. 10), and hence the OBR-side film heat transfer coefficient (Eq. 11) and Nusselt number (Eq. 12) could be found. 


$$
\begin{aligned}
& Q=U A \Delta T_{L M} F=m_{O B R} c_{p} \Delta T_{O B R} \\
& R_{\text {tot }}=\sum R_{i}=R_{O B R}+R_{\text {wall }}+R_{\text {shell }}=\frac{1}{U} \\
& R_{O B R}=\frac{1}{h_{O B R}} \\
& N u=\frac{h_{O B R} D}{k}
\end{aligned}
$$

Where $\mathrm{Q}$ is the overall heat transfer duty $(\mathrm{W}), \mathrm{A}$ is the heat transfer area $\left(\mathrm{m}^{2}\right), \Delta T_{L M}$ the $\log$ mean temperature difference $(\mathrm{K}), \mathrm{F}$ is the correction factor which is 1 for pure counter-current flow, $m_{O B R}$ is the mass flow rate $(\mathrm{kg} / \mathrm{s})$ of the OBR-side fluid, $c_{p}$ is the specific heat capacity of the OBR-side fluid $(\mathrm{J} / \mathrm{kg}-\mathrm{K})$, $\triangle T_{O B R}$ is the temperature difference $(\mathrm{K})$ between the OBR inlet and outlet, $\mathrm{R}$ is the thermal resistance (tot $=$ total, $\mathrm{i}=$ individual component, $\mathrm{OBR}=\mathrm{OBR}$-side convective resistance, wall $=$ wall conductive resistance, shell $=$ shell-side convective resistance), $h_{O B R}$ is the film heat transfer coefficient on the OBRside, $\mathrm{k}$ is the thermal conductivity of the OBR-side fluid, and $\mathrm{Nu}$ is the Nusselt number of the OBR.

\subsubsection{Effect of net flow}

Fig. 6 (a) and (b) summarise the enhancement of the OBR-side Nusselt number determined over a steady flow in a smooth tube $\left(N u_{o}\right)$ for all the designs at $R e_{o}=360$ (Fig. 6 (a)), and $R e_{o}=1080$ (Fig. 6 (b)).
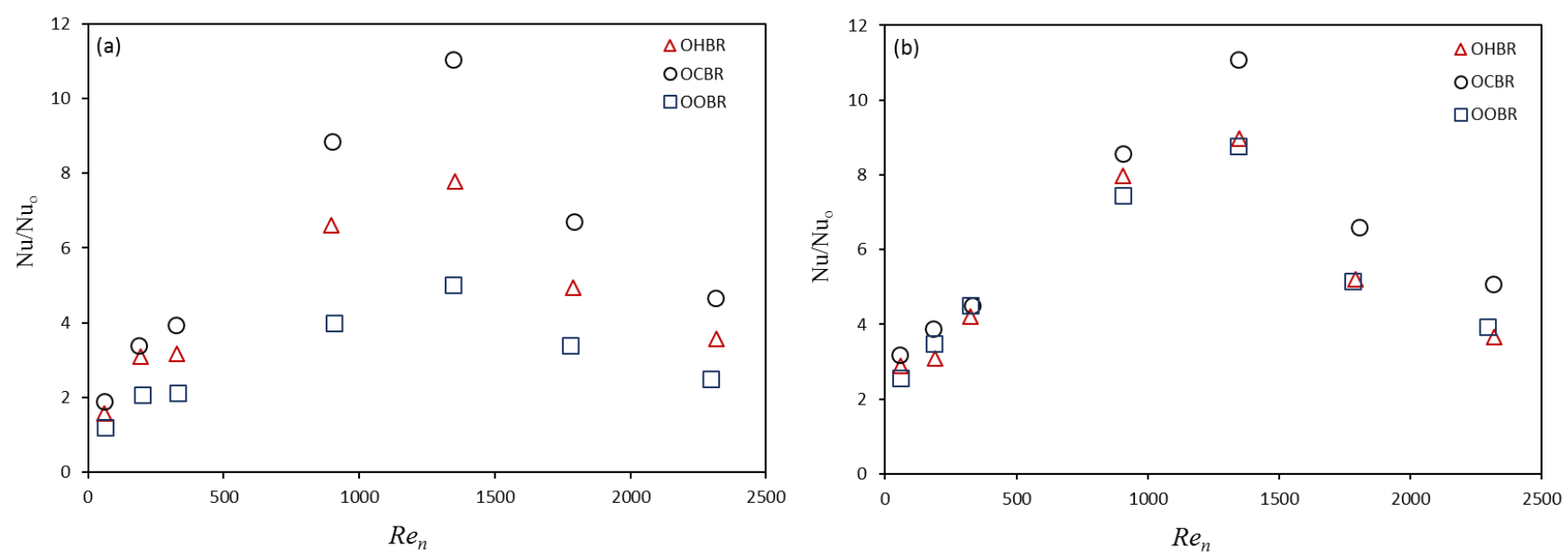

Fig. 6: OBR-side Nusselt number enhancement: Effect of net flow Reynolds number for a) $R_{0}=360$ $\left(x_{o}=2 \mathrm{~mm}, f=4 \mathrm{~Hz}\right)$, and $\left.\mathrm{b}\right) \mathrm{Re}_{o}=1080\left(x_{o}=4 \mathrm{~mm}\right.$ and $\left.f=6 \mathrm{~Hz}\right):$ where OHBR is oscillatory helical baffled meso-reactor, OCBR is oscillatory central baffled meso-reactor (OCBR), and OOBR is oscillatory orifice baffled meso-reactor. 
As seen in Fig. 6, the $N u$ enhancement had the same trend for all the OBR designs where it increased significantly with net flow to achieve a maximum enhancement of 9-11-fold at $\operatorname{Re}_{\mathrm{n}}=1345$. Then the enhancement decreased to 2.5- 4.5-fold at $\mathrm{Re}_{\mathrm{n}}=2300$. The reason for this is likely because of the forward net flow dominating at higher $\mathrm{Re}_{\mathrm{n}}$ : the oscillatory flow component was not of sufficient strength to reverse the flow meaning vortex formation only occurred in the forward direction (in front of each baffle). Hence, the magnitude of radial mixing compared to axial mixing decreased, leading to lower levels of enhancement.

At both oscillation conditions, $\operatorname{Re}_{0}=360$ and 1080, OCBR shows the highest $\mathrm{Nu}$ enhancement because the central blockage causes greater disruption of the axial flow towards the radial direction, resulting in toroidal flow around the central disc [6]. Consequently, this leads to significant boundary layer disruption and significantly enhanced rates of convection. The OHBR shows higher $\mathrm{Nu}$ enhancement than OOBR at $\mathrm{Re}_{\mathrm{o}}=360$ indicating swirling flow formation, hence mixing enhances [10]. However, at $\operatorname{Re}_{0}=1080$, it shows insignificant enhancement indicating chaotic mixing formation $[4,5,10]$ for both baffle designs.

Increasing mixing intensity, $\mathrm{Re}_{\mathrm{o}}$, from 360 to 1080 led to higher enhancement in heat transfer for the helical and orifice baffle designs, but had no effect for the central baffle design. This is probably due to the central baffle geometry which induces chaotic flow to occur at lower oscillation intensities than those required by the OHBR and OOBR $[6,9,10]$.

\subsubsection{Effect of oscillatory Reynolds number}

The effect of mixing intensity, $\mathrm{Re}_{\mathrm{o}}$, on the $\mathrm{Nu}$ enhancement is presented in Fig. 7, below:
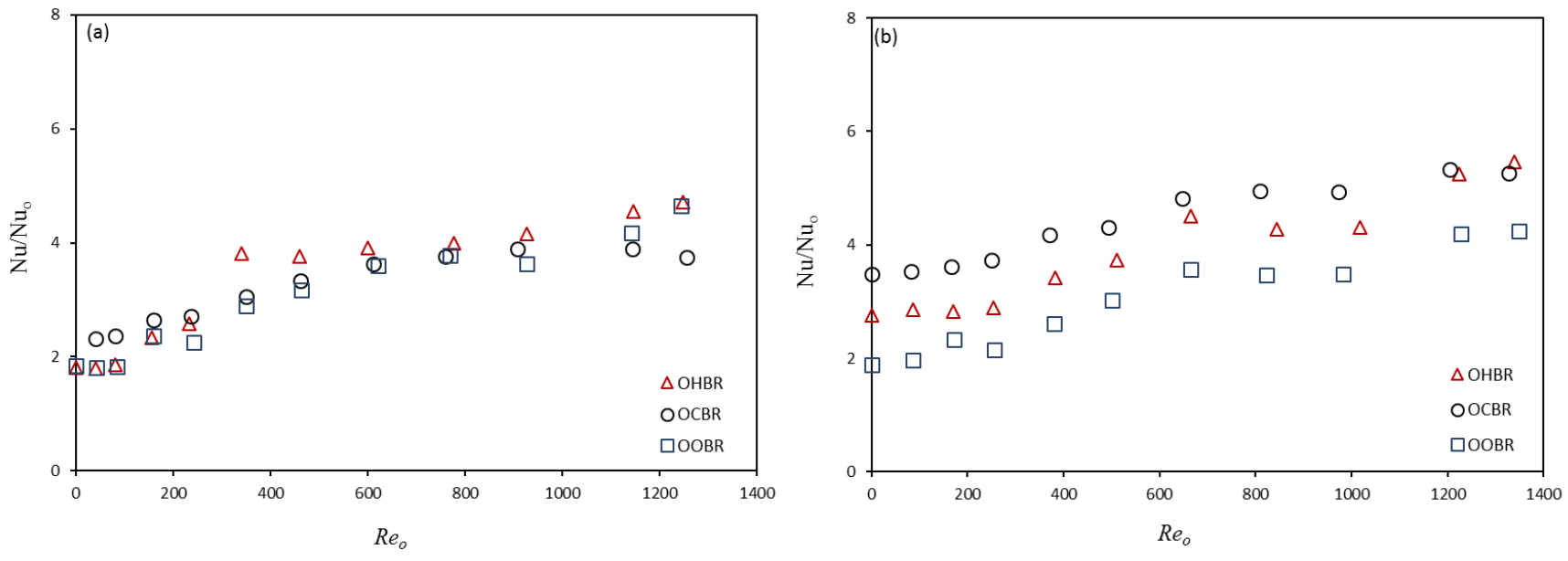

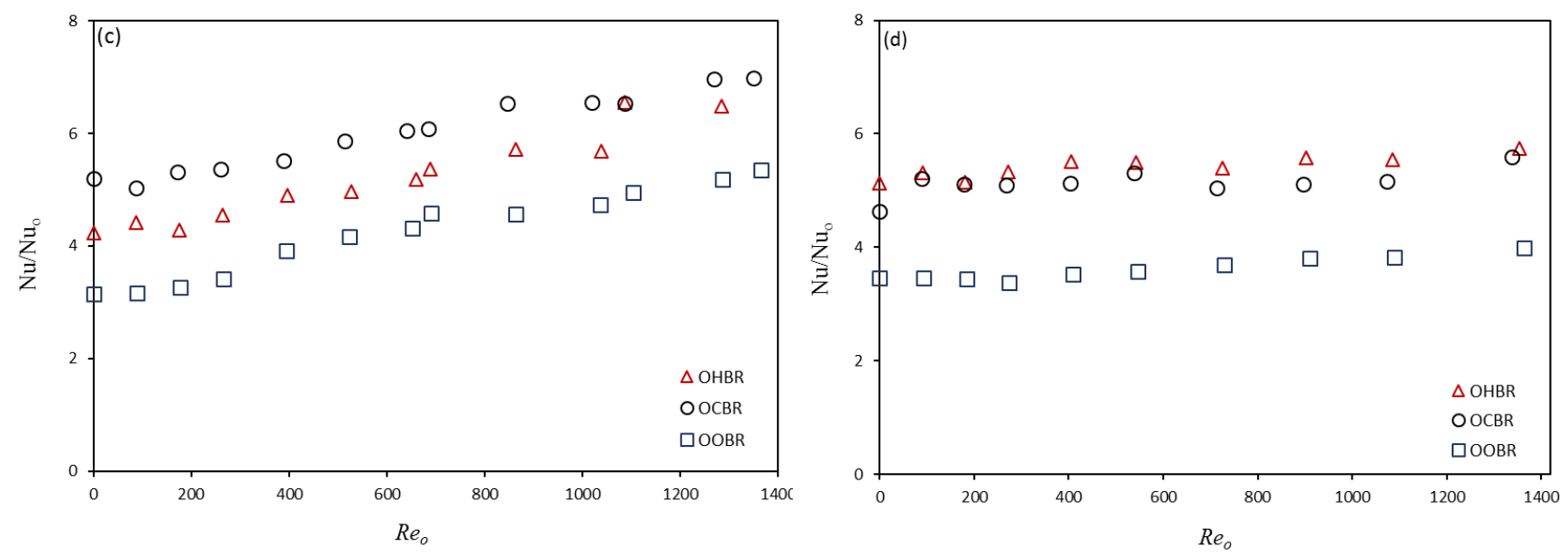

Fig. 7: Effect of oscillation conditions, Re, on the OBR-side Nusselt number enhancement over a steady flow in a smooth tube $\left(\mathrm{Nu} / \mathrm{Nu} u_{o}\right)$ at different net flows: a) $\left.\left.R e_{n}=65, b\right) R e_{n}=195 \mathrm{c}\right) \operatorname{Re}_{n}=330$, and d) $R e_{n}=$ 700 where OHBR is oscillatory helical baffled meso-reactor, OCBR is oscillatory central baffled mesoreactor (OCBR), and OOBR is oscillatory orifice baffled meso-reactor.

At $R e_{n}<400$ (Fig. 7 (a) to (c)), $N u$ increased significantly with increasing $R e_{o}$. This is due to improved radial mixing as a result of the periodic vortices generated interrupting the thermal boundary layer. The highest enhancements can be observed at $\operatorname{Re}_{n}=195$ (Fig. 7 (b)) and 330 (Fig. 7 (c)) when $R e_{o}$ is greater than around 600. This corresponds velocity ratios (Eq. 6) of around $2.5 \leq \psi \leq 9$. This is in agreement with Phan and Harvey (2010) [4] where the optimal range of $\psi$ to achieve mixing enhancement in meso-OBRs was 4-10. At $R e_{n}=700$ (Fig. 7(d)), $R e_{o}$ had a small effect on $N u$ because the flow already showed turbulent characteristics due to the combined effect of relatively high net flow velocity and disturbance due to the baffle. Hence, radial transport is already high, so further significant enhancement in the heat transfer is not possible. These results agree with various existing studies (on larger diameter OBRs) $[1,2,3]$.

Table 3 summarises the maximum enhancement in $N u$ over the steady flow in a smooth tube $\left(N u / N u_{o}\right)$ where the OCBR exhbited the highest enhancement than the other OBR designs.

Table 3: Summary of the Nu enhancement in the OBRs

\begin{tabular}{|l|c|c|c|c|}
\hline & \multicolumn{4}{|c|}{$N u$ enhancement $\left(N u / N u_{o}\right)$, fold } \\
\hline & $R e_{n}=65$ & $R e_{n}=195$ & $R e_{n}=330$ & $R e_{n}=700$ \\
\hline OHBR & 4.65 & 5.25 & 6.50 & 5.60 \\
\hline OCBR & 4.65 & 5.25 & 7.00 & 5.60 \\
\hline OOBR & 3.75 & 4.24 & 5.35 & 4.00 \\
\hline
\end{tabular}




\subsubsection{Correlation for predicting heat transfer coefficients in OBRs}

Correlations for predicting $\mathrm{Nu}$ were established, Eq. 13 (a)-(c) at $0<R e_{0} \leq 1300$, by developing Eq. 6 (a) and (b) to fit the experimental data collected from the three OBR designs using the Microsoft Excel solver add-in (GRG non-linear algorithm). Therefore, Eq. 13 (a-c) is of the same form as Eq. 6 (a) except the constant which depends on the OBR scale and baffle design. The Ren and Reo exponents in each correlation, Eq. 13 (a-c) and Eq. 6 (a), are the same as the Nu enhancements for all the OBRs exhibited broadly the same behaviour (see Fig. 5 and 6, and [3]).

At $0<R e_{o} \leq 1300$ :

$$
\begin{aligned}
& N u=0.007 R e_{n}^{0.7} \operatorname{Re}_{o}^{0.44} \operatorname{Pr}^{0.3} \quad \text { Orifice baffle design, OOBR } \\
& N u=0.009 R e_{n}^{0.7} \operatorname{Re}_{0}^{0.44} \mathrm{Pr}^{0.3} \quad \text { Helical baffle design, OHBR } \\
& N u=0.011 \operatorname{Re}_{n}^{0.7} \operatorname{Re}_{o}^{0.44} \operatorname{Pr}^{0.3} \quad \text { Central axial baffle design, OCBR }
\end{aligned}
$$

Fig.8 (below) shows the validity test for the developed correlations. The predicted $N u$ using the developed correlations, Eq. 13 (a)-(c), is plotted against the experimentally of $\mathrm{Nu}$ collected here from this work and from literature $[1,3] .85 \%$ of the data falls within $\pm 30 \%$ confidence limits, hence these correlations could be applied to predict heat transfer performance of OBRs within the range of experiments investigated here.

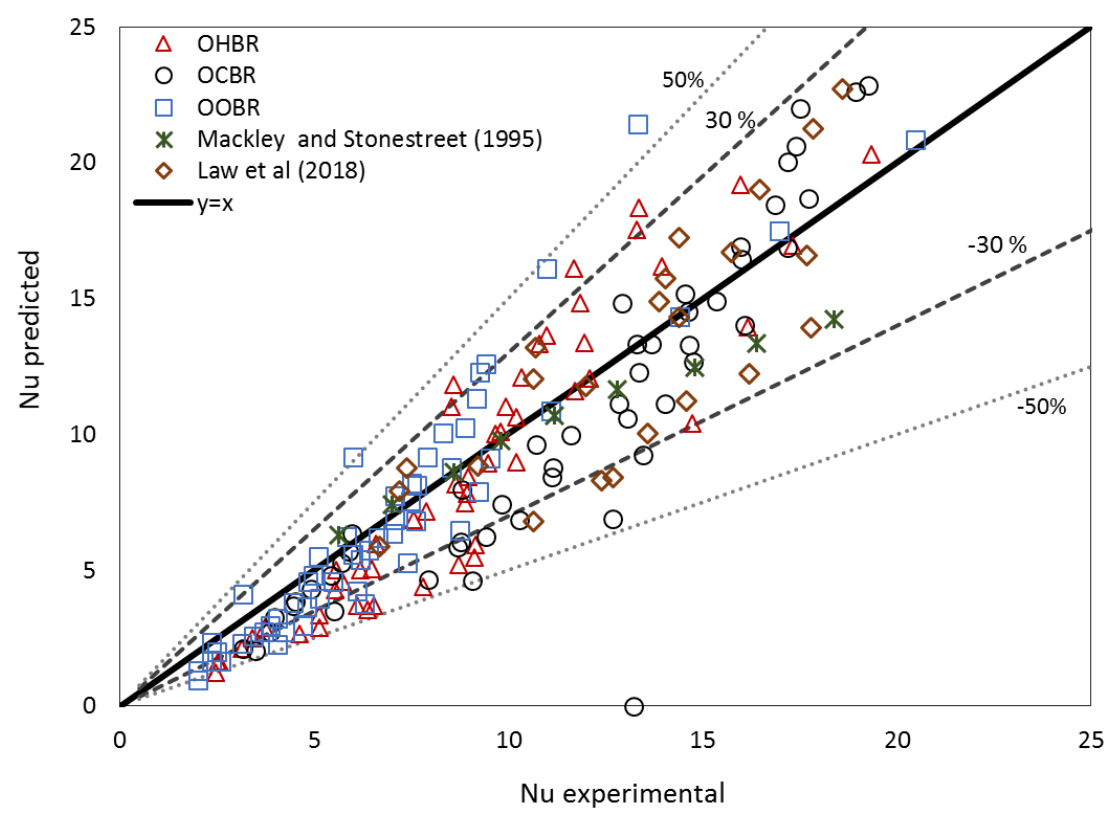


Fig. 8. Comparison of Nusselt number prediction by correlations and experimental results from this work and from literature $[1,3]$

A new general form of the correlation to predict Nusselt numbers can now be proposed as follows (Eq. 14a and 14b), where $\lambda$ is the coefficient of thermal performance which is dependent on the tube diameter and internals. The differing values of $\lambda$ for each scale/baffle design accounts for how the mixing in OBRs differs depending on these design parameters, as shown in various previous works $[4,5,6,8,10]$. Table 4 shows the coefficients of thermal performance which have been established to date, and $\mathrm{R}^{2}$ values indicating how well each correlation fits the experimental data.

At $0<R e_{o} \leq 1300$ :

$N u=\lambda \operatorname{Re}_{n}^{0.7} \operatorname{Re}_{o}^{0.44} \operatorname{Pr}^{0.3}$

At $R e_{o}>1300$ :

$N u=23.45 \lambda \operatorname{Re}_{n}^{0.7} \operatorname{Re}_{o}^{0.44} \operatorname{Pr}^{0.3}$

Table 4: Proposed values of coefficient of thermal performance for use in Eq. 14.

\begin{tabular}{|c|c|c|c|c|c|c|}
\hline \multirow{2}{*}{ Baffle Design } & \multirow{2}{*}{ Tube Diameter } & \multirow{2}{*}{$\begin{array}{c}\text { Coefficient of } \\
\text { thermal } \\
\text { performance }\end{array}$} & \multirow{2}{*}{$\mathrm{R}^{2}$} & \multicolumn{3}{|c|}{ Range of applicability $^{1}$} \\
\cline { 5 - 7 } & & 0.009 & 0.93 & $61-2400$ & $\leq 1550$ & 4.4 \\
\hline Helical & 5 & 0.011 & 0.93 & $61-2400$ & $\leq 1550$ & 4.4 \\
\hline Central & 5 & 0.007 & 0.91 & $61-2400$ & $\leq 1550$ & 4.4 \\
\hline Orifice & 5 & 0.022 & 0.87 & $\leq 1200$ & $\leq 800$ & 73 \\
\hline Orifice & 12 & 0.022 & 0.95 & $200-1300$ & $\leq 8700$ & $4.4-73$ \\
\hline Orifice & 25 & & $R_{\mathrm{n}}$ & $\operatorname{Pr}$ \\
\hline
\end{tabular}

${ }^{1}$ Correlation may be valid outside of this range, but this is the proven range to date.

\subsection{Thermal performance of meso-OBR}

In order to quantify the effect of both Nusselt number enhancement and pressure drop penalty into one single measure, an adapted version of the third form of Thermal Performance (TH) criterion suggested by Zimparov [11] has been used (Eq. 15). Here, the friction factor term has been replaced by the pressure drop to allow for comparison between both steady and oscillatory flow cases (comparing the friction factor would only allow comparison between baffle types, and not between the steady and oscillatory flow cases). 
Thermal performance $(T H)=\left(\frac{N u}{N u_{o}}\right) /\left(\frac{\Delta P}{\Delta P_{o}}\right)^{1 / 3}$

Where $N u$ is the OBR-side Nusselt number, $N u_{o}$ is the smooth tube-side Nusselt number at $\operatorname{Re}_{0}=0, \Delta \mathrm{P}$ is the OBR-side pressure drop (bar) at $\mathrm{Re}_{\mathrm{o}}>0$ and $\Delta \mathrm{P}_{\mathrm{o}}$ is pressure drop (bar) for the smooth tube at $\mathrm{Re}_{\mathrm{o}}=0$.

Fig. 9 shows the effect of the baffle design and $R e_{n}$ on the thermal performance for the steady flow case $\left(\operatorname{Re}_{\mathrm{o}}=0\right)$.

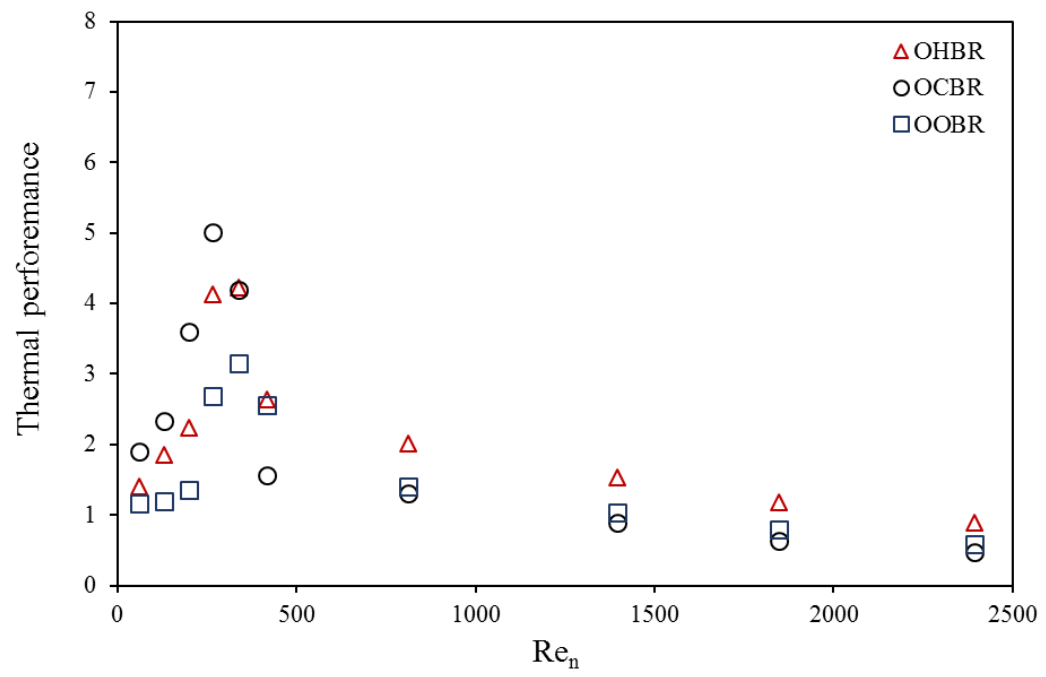

Fig. 9: Effect of net flow only on the thermal performance of the meso-OBRs (oscillatory helical baffled meso-reactor (OHBR), oscillatory central baffled meso-reactor (OCBR), and oscillatory orifice baffled meso-reactor $(O O B R))$ for non-oscillation, Reo $=0$

In Fig. 9, the thermal performance every design increased significantly with increasing the net flow until a maximum of 4-5 was reached at $R e_{n} \approx 400$, depending on the baffle design. For $R e_{n}>400$ the thermal performance then decreased monotonically. As discussed in Section 3.1.1, at $\operatorname{Re}_{n}>400$ the pressure drop rises sharply due to the flow beginning to show turbulent characteristics. While this will induce vortices in the OBRs resulting in mixing enhancement [4], shear stress will be induced leading to high friction and pressure drop. Hence, at this point the pressure drop penalty rises at a rate not sustained by the Nusselt number enhancement and the overall thermal performance decreases. This trend agrees with that for baffled tubes, without oscillation, in literature $[8,11,12]$.

At $\operatorname{Re}_{n}<400$, considered the laminar regime for this system, the OCBR exhibited the highest thermal performance, whereas at $R e_{n}>400$ the OHBR exhibited the highest thermal performance. This reflects the fact that the OHBR had the lowest pressure drop (see Fig. 3). 
Fig. 10 shows the effect of baffle design and $R e_{o}$ on the thermal performance for constant $R e_{n}$.
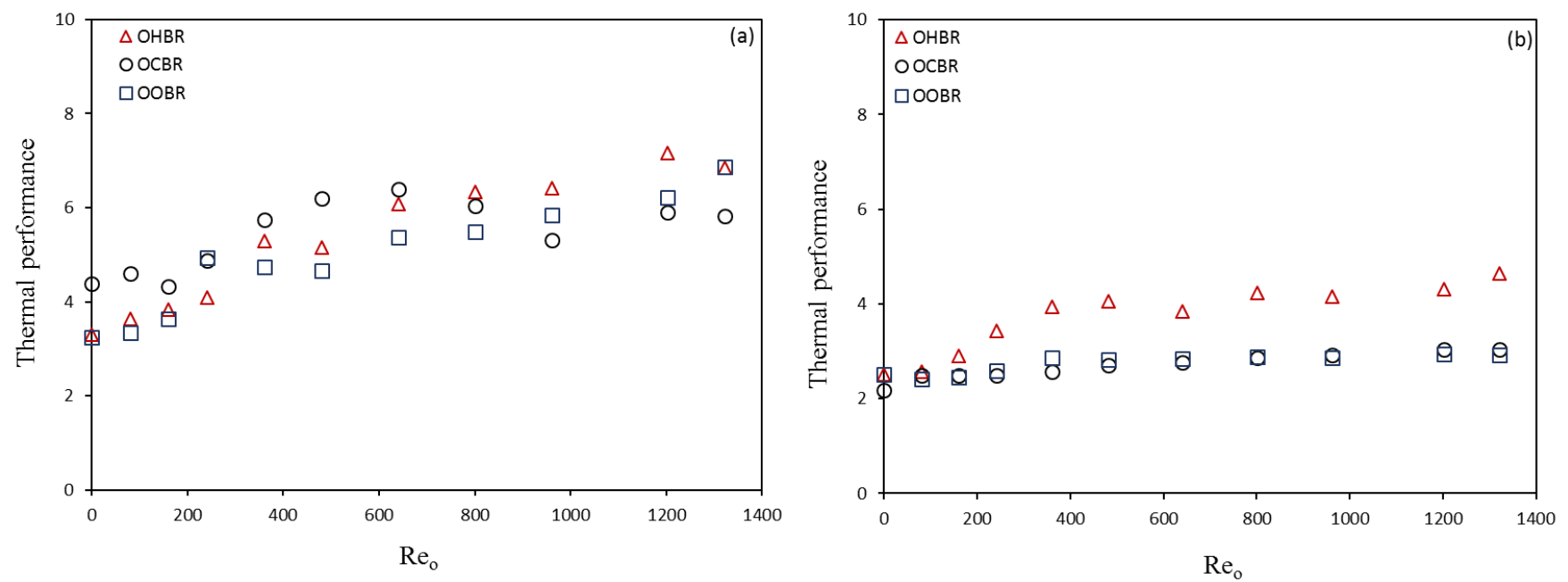

Fig. 10: Effect of oscillatory flow on the thermal performance of the meso-OBRs (oscillatory helical baffled meso-reactor (OHBR), oscillatory central baffled meso-reactor (OCBR), and oscillatory orifice baffled meso-reactor (OOBR)) at: a) $\operatorname{Re}_{n}=340$, and b) $R e_{n}=640$

When oscillation was applied, the thermal performance of the meso-OBRs exhibited different trends to those without oscillation. At $R e_{n}=340$, in the net flow laminar regime (Fig. 10 (a)), the thermal performance of the meso-OBRs increased with increasing $R e_{o}$, except for the OCBR performance, which started decreasing at $R e_{o} \geq 800$. This is due to the relatively high pressure drop of the OCBR, which was the highest at $R e_{o} \geq 800$. The OHBR exhibits the highest thermal performance of $480 \%$, compared to $460 \%$ for the OCBR and $300 \%$ for the OOBR. In addition, at $R e_{n}=640$ (Fig. 10 (b)), the thermal performances of the OCBR and OOBR are approximately constant over the $\mathrm{Re}_{\mathrm{o}}$ range applied as they both exhibited high pressure drops in this regime, counteracting any heat transfer improvements. However, in the same regime, $\mathrm{Re}_{\mathrm{n}}=640$, OHBR has shown slightly higher improvement in thermal performance than OCBR and OOBR. Unlike in Fig. $9\left(R e_{o}=0\right)$, the trends of TH data here in Fig. 10 (a) and (b) differ due to the different flow pattern of the fluid with applying oscillation where secondary mixing occurs as a result of formation of recirculation zones in the baffle cavities $[4,8,10]$. However, at $R e_{n}=640$ (Fig. 10 (b)), lower thermal performance is observed comparing with that at laminar flow, $R e_{n}=340$ (Fig. 10 (b)) as a result of the high pressure drops observed which affected the thermal performance according to Eq. 17. 


\section{Conclusions}

The effects of net flow, oscillatory flow and baffle design on heat transfer in mesoscale oscillatory baffled reactors were investigated. Thermal performance was used to compare the designs, as it takes into account both heat transfer and pressure drop. Here, the thermal performance was defined with respect to the net flow-only case.

The addition of oscillatory flow increased heat transfer $(\mathrm{Nu})$ and thermal performance in all cases. Enhancement factors in $N u$ (vs net flow $N u$ ) were as high as 7, for very high $\mathrm{Re}_{\mathrm{o}}$ (over 1000). Interestingly, applying oscillatory flow, reduced the pressure drop when operating in the laminar regime, and had no effect in the turbulent regime.

The central baffled design incurred the highest pressure drop, while the helical baffled design had the lowest. Hence, although the heat transfer enhancement in the OCBR was relatively high, it's thermal performance was not, as the pressure drop "cost" was significant. Conversely the highest thermal performance (up to 7.2) were observed in the helically baffled design, where $\mathrm{Nu}$ was enhanced without such substantial pressure drop increases.

New correlations for predicting tube-side pressure drops and Nusselt numbers were established for each meso-OBR design based on the experimental data. All the developed correlations broadly agreed with experimental results to $\pm 30 \%$, t. This degree of accuracy is similar to that in many existing well-used heat and mass transfer correlations, and would usually be accurate enough for design purposes.

\section{Acknowledgements}

Financial support from the Higher Committee for Education Development in Iraq (HCED) to author Safaa M. R. Ahmed is gratefully acknowledged.

This study was in part completed by Richard Law under funding from the Newcastle University Institute for Sustainability (grant no. BH160493).

\section{References}

[1] M.R. Mackley, P. Stonestreet, Heat transfer and associated energy dissipation for oscillatory flow in baffled tubes, Chem. Eng. Sci., 50(1995) 2211-2224.

[2] G.G. Stephens, M.R. Mackley, Heat transfer performance for batch oscillatory flow mixing, Exp. Therm. Fluid Sci., 25(2002)583-594 
[3] R. Law, S.M.R. Ahmed, N. Tang, A.N. Phan, A.P. Harvey, Development of a more robust correlation for predicting heat transfer performance in oscillatory baffled reactors, Chem. Eng. Process., 125(2018)133-138.

[4] A.N. Phan, A. Harvey, Development and evaluation of novel designs of continuous mesoscale oscillatory baffled reactors, Chem. Eng. J., 159(2010) 212-219.

[5] S.M.R. Ahmed, A.N. Phan, A.P. Harvey, Scale-Up of Oscillatory Helical Baffled Reactors Based on Residence Time Distribution, Chem. Eng. Tech., 40(2017) 907-914.

[6] A. Mazubert, D.F. Fletcher, M. Poux, J. Aubin, Hydrodynamics and mixing in continuous oscillatory flow reactors-Part I: Effect of baffle geometry, Chem. Eng. Process., 108(2016)7892.

[7] D. González-Juárez, J.P. Solano, R. Herrero-Martín, A.P. Harvey, Residence time distribution in multiorifice baffled tubes: A numerical study, Chem. Eng. Res. Design, 118(2017)259-69.

[8] J.P. Solano, R. Herrero, S. Espín, A.N. Phan, A.P. Harvey, Numerical study of the flow pattern and heat transfer enhancement in oscillatory baffled reactors with helical coil inserts, Chem. Eng. Res. Design, 90(2012) 732-742.

[9] M.E. Mackley, M.R. Mackley, Y. Wang, Oscillatory flow within tubes containing wall or central baffles, Institution Chem. Eng. 69(1991)506-513.

[10] J.R. McDonough, S.M.R. Ahmed, A.N. Phan, A.P. Harvey, A study of the flow structures generated by oscillating flows in a helical baffled tube, Chem. Eng. Sci. 171(2017)160-178.

[11] V. Zimparov, Enhancement of heat transfer by a combination of a single-start spirally corrugated tubes with a twisted tape, Exp. Therm. Fluid Sci., 25(2002) 535-546.

[12] A. Garcia, P.G. Vicente, A. Viedma, Experimental study of heat transfer enhancement with wire coil inserts in laminar-transition-turbulent regimes at different Prandtl numbers, Int. J. Heat Mass Transfer, 48(2005)4640-4651. 